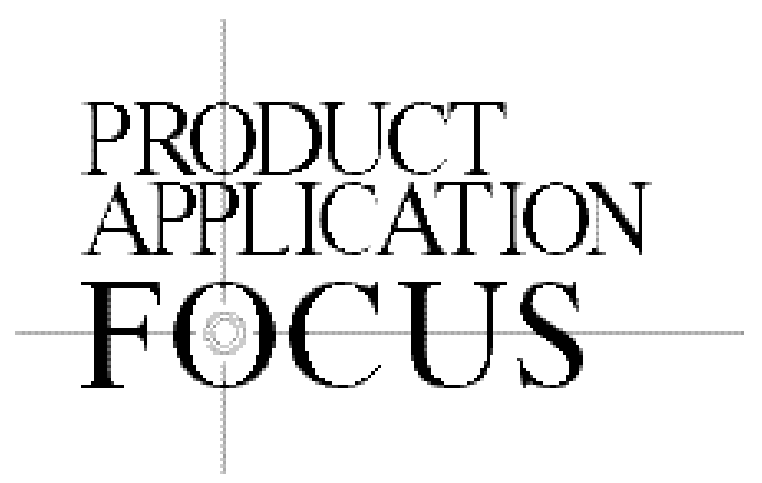

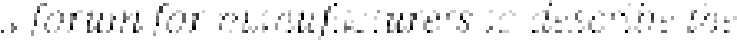

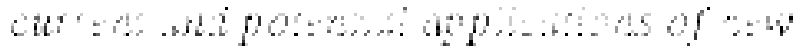

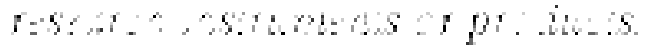

\title{
Poly (ADP-Ribose) Polymerase Cleavage Monitored In Situ in Apoptotic Cells
}

\author{
Martha A. O'Brien, Richard A. Moravec, and Terry L. Riss \\ Promega Corporation, Madison, WI, USA
}

BioTechniques 30:886-891 (April 2001)

\begin{abstract}
During apoptosis, the activation of a family of cysteine proteases, or caspases, results in proteolytic cleavage of numerous substrates. Antibody probes specific for neoepitopes on protein fragments generated by caspase cleavage provide a means to monitor caspase activity at the level of the individual cell. Poly (ADP-ribose) polymerase (PARP), a nuclear enzyme involved in DNA repair, is a well-known substrate for caspase-3 cleavage during apoptosis. Its cleavage is considered to be a hallmark of apoptosis. Here, we demonstrate that an affinity-purified polyclonal antibody to the p85 fragment of PARP is specific for apoptotic cells. Western blots show that the antibody recognizes the 85-kDa (p85) fragment of PARP but not full-length PARP. We demonstrate a time course of PARP cleavage and DNA fragmentation in situ using the PARP p85 fragment antibody and terminal deoxynucleotidyl transferase-mediated dUTP nick end labeling (TUNEL) in Jurkat cells treated with anti-Fas. Furthermore, our results indicate that the p 85 fragment of PARP resulting from caspase cleavage during apoptosis is rapidly localized outside the condensed chromatin but not in the cytoplasm.
\end{abstract}

\section{INTRODUCTION}

Apoptotic death requires the controlled degradation of the cell. Proteases play a crucial role in this programmed cell death or apoptosis. The first protease identified as having a function in the apoptosis pathway was the Caenorhabditis elegans, ced-3 gene product, a cysteine aspartic acid-specific protease, or caspase (35). There are now numerous known caspases that are important to apoptosis in most eukaryotic cells (31). Many target-specific substrates for caspases have been identified, including the DNA repair enzyme, poly (ADP-ribose) polymerase (PARP), actin, lamins, fodrin, gel- solin, the DNase inhibitor, ICAD, cytokeratin, and others $(12,31,34)$. Antibodies to caspase substrates have been used extensively for western blotting; however, only recently have antibodies been developed to specific neoepitopes produced by caspase cleavage $(13,22,29,34)$. Antibodies to specific neoepitopes provide markers for specific and early events in apoptosis. In this study, we focus on the caspase substrate, PARP, to generate a neoepitope-specific antibody.

PARP is a nuclear DNA-binding protein that detects DNA strand breaks and functions in base excision repair (32). PARP is now called PARP-1 because of the recent identification of other related enzymes $(2,5)$ but will be referred to here as PARP for simplicity. PARP is activated upon binding to DNA strand breaks. During apoptosis, PARP is cleaved into 85- and $29-\mathrm{kDa}$ fragments that no longer support the enzymatic DNA repair function (1). It has been suggested that the small fragment containing the DNA-binding domain of cleaved PARP may inhibit access by other repair enzymes (28). The other 85$\mathrm{kDa}$ fragment has been hypothesized to be localized to the nucleoplasm during apoptosis to modulate the activity of other proteins involved in apoptosis, such as p53 $(1,16)$.

PARP is a well-established substrate for caspase- $3(4,12$, 17,30). Caspase-7 is also likely to cleave PARP in vivo (7). Western blot detection of PARP cleavage has been used extensively as an indicator of apoptosis $(6,8-10,23,26,27)$. PARP is cleaved between $\mathrm{Asp}_{213}$ and $\mathrm{Gly}_{214}$ in the human sequence (6), producing two fragments of apparent molecular weights of 25 and $85 \mathrm{kDa}$. From sequence data, the fragments are now designated as 24 and $89 \mathrm{kDa}$; here, the large fragment is designated as $85 \mathrm{kDa}(\mathrm{p} 85)$ to be consistent with past studies.

We have generated a polyclonal antibody (pAb) directed against a peptide derived from the newly formed $\mathrm{N}$-terminus of the large fragment of human PARP resulting from caspase- 
3 cleavage. We show its utility as a marker for apoptosis using a model system of anti-Fas-induced apoptosis in Jurkat cells (33). We provide a chronology of apoptotic events in this model system by monitoring DNA fragmentation and PARP cleavage, both in situ and in vitro, during a time course study. Finally, we use double labeling to localize the p85 fragment in cells during apoptosis.

\section{MATERIALS AND METHODS}

\section{Antibody Production and Affinity Purification}

The PARP immunogen was a synthetic peptide, gly-valasp-glu-val-ala-lys (GVDEVAK), representing the N-terminus of the large $\mathrm{C}$-terminal fragment of human PARP that results from caspase- 3 cleavage. The peptide was modified to contain a short spacer molecule and a $\mathrm{C}$-terminal cysteine and coupled to keyhole limpet hemocyanin (KLH) carrier protein. The antigen complex was injected into rabbits to produce antiserum using standard methods. An affinity purification column was made by covalently linking the peptide antigen via the C-terminal cysteine to Sulfolink resin (Pierce Chemical, Rockford, IL, USA) at $1 \mathrm{mg}$ peptide/mL resin. The antiserum was then affinity purified on this column. We have designated the affinity-purified polyclonal antibody as Anti-PARP p85 Fragment pAb (Promega, Madison, WI, USA). It is abbreviated as anti-PARP p85 pAb.

\section{Cell Culture and Induction of Apoptosis}

Apoptosis was induced in two model cell culture systems. Jurkat cells were treated with an anti-Fas monoclonal $\mathrm{Ab}$ (Clone CH-11; Oncor, Gaithersburg, MD, USA or PanVera, Madison, WI, USA) and SH-SY5Y cells were induced to undergo apoptosis with the kinase inhibitor, staurosporine (Sigma, St. Louis, MO, USA). Jurkat cells were grown in RPMI-

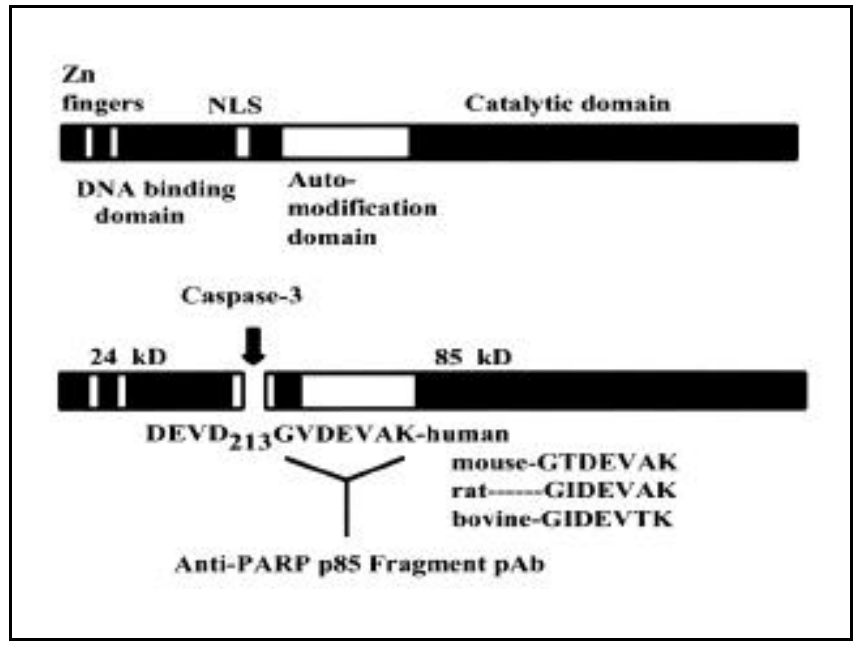

Figure 1. The anti-PARP p85 pAb is specific for the 85-kDa caspasecleaved PARP fragment. A schematic of the PARP protein shows caspase- 3 cleavage and the sequence for the immunogen (A). The DNA-binding domain has two zinc fingers and a bipartite nuclear localization signal (NLS) (6). Caspase-3 cleaves PARP within the NLS after the Asp. The anti-PARP p85 fragment $\mathrm{pAb}$ is directed against a short peptide just $\mathrm{C}$-terminal to the cleavage site in human PARP. The homologous sequences in mouse, rat, and bovine are shown.
1640 medium (Sigma) plus 10\% fetal bovine serum (HyClone Laboratories, Logan, UT, USA). Cells were counted, resuspended in fresh medium to $5 \times 10^{5} / \mathrm{mL}$, and treated with anti-Fas $\mathrm{mAb}(0.05 \mu \mathrm{g} / \mathrm{mL})$ for varying times at $37^{\circ} \mathrm{C}$. Control cells were left untreated. After treatment, cells were harvested by centrifugation at $250-350 \times g$ to pellet cells, washed in cold PBS, and centrifuged again. Pellets were resuspended in PBS at $1.5 \times 10 \% / \mathrm{mL}$ for microscope slide preparation for immunocytochemistry or resuspended in lysis buffer for cell extract preparation.

SH-SY5Y cells (ATCC, Manassas, VA, USA) were grown in DME/F12 medium (Sigma) and 10\% fetal bovine serum (HyClone Laboratories). Cells were grown in chamber slides and treated with staurosporine $(0.5 \mu \mathrm{M})$ or a DMSO (Sigma) vehicle control for various times. After treatment, slides were rinsed in PBS and prepared for immunocytochemistry.

\section{Western Blotting}

Cell extracts were prepared by resuspending pellets in lysis buffer consisting of $25 \mathrm{mM}$ HEPES, $5 \mathrm{mM} \mathrm{MgCl} 2,5 \mathrm{mM}$ EDTA, $5 \mathrm{mM}$ dithiothreitol (DTT), $2 \mathrm{mM}$ PMSF, $10 \mu \mathrm{g} / \mathrm{mL}$ Pepstatin A, and $10 \mu \mathrm{g} / \mathrm{mL}$ Leupeptin. After four freeze-thaw cycles, extracts were centrifuged for $20 \mathrm{~min}$, and supernatants were harvested. Samples $(10 \mu \mathrm{g})$ were subjected to reducing SDS-PAGE and transferred to nitrocellulose using standard methods. After blocking in Tris-buffered saline and $0.05 \%$ Tween ${ }^{\circledR} 20$ (Sigma) (TBST) and 1\% BSA, the blots were incubated in the anti-PARP p $85 \mathrm{pAb}(0.75 \mu \mathrm{g} / \mathrm{mL}$ in TBST and $0.1 \% \mathrm{BSA})$. After rinsing, the membranes were incubated in donkey anti-rabbit alkaline phosphatase-conjugated antibody (1:5000; Jackson ImmunoResearch Laboratories, West

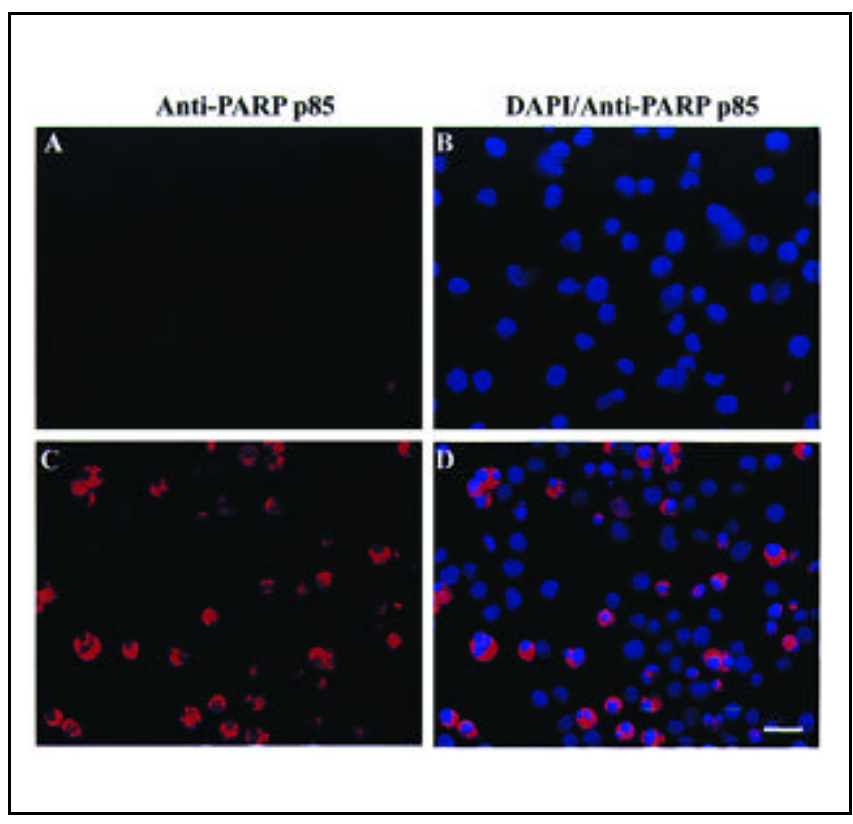

Figure 2. The anti-PARP p85 pAb is specific for apoptotic cells. Jurkat cells were either untreated (A and B) or treated with $0.05 \mu \mathrm{g} / \mathrm{mL}$ anti-Fas $\mathrm{mAb}$ for $6 \mathrm{~h}(\mathrm{C}$ and $\mathrm{D})$. Immunostaining with anti-PARP $\mathrm{p} 85$ fragment revealed minimal background staining in the untreated cells (A), whereas many cells were stained in the treated cells $(\mathrm{C})$. Double labeling illustrated that the cells with condensed chromatin and apoptotic nuclei were stained with the anti-PARP p85 pAb (B and D). The double labeling also revealed that the anti-PARP $\mathrm{p} 85$ fragment was segregated from the condensed chromatin (D). Scale bar $=20 \mu \mathrm{m}$. 
Grove, PA, USA). The blots were developed with 5-bromo-4chloro-3-indoyl phosphate/nitroblue tetrazolium (Western Blue ${ }^{\circledR}$; Promega).

\section{Immunocytochemistry}

Anti-Fas mAb-treated and control Jurkat cells $\left(1.5 \times 10^{6}\right.$ cells $/ \mathrm{mL}$ ) were added to poly-L-lysine (Sigma)-coated slides (Cel-Line Associates, Portsmouth, NH, USA). The cells were not allowed to dry before fixing in either $10 \%$ buffered formalin or 4\% paraformaldehyde for $25-30 \mathrm{~min}$ at room tem perature. The adherent control and staurosporine-treated $\mathrm{SH}$ SY5Y cells were fixed in the same manner. The cells were permeabilized with $0.2 \%$ Triton ${ }^{\circledR} \mathrm{X}-100$ (Sigma), incubated in blocking solution (5\% horse serum in PBS/0.1\% Tween 20), followed by incubation in the anti-PARP p85 pAb $(2.5$ $\mu \mathrm{g} / \mathrm{mL})$. For double labeling, an anti-ßIII tubulin mAb (1 $\mu \mathrm{g} / \mathrm{mL}$; Promega) was added with the anti-PARP p85 pAb. After rinsing several times in PBS, the slides were incubated in donkey anti-rabbit $\mathrm{Cy}^{\mathrm{TM}} 3$-conjugated antibody (1:500) for the anti-PARP p85 pAb or in donkey anti-mouse FITC-conjugated antibody (1:500) for the anti- $\beta$ III tubulin mAb (both from Jackson ImmunoResearch Laboratories). The slides were mounted in Vectashield ${ }^{\circledR}$ Mounting Medium plus DAPI (Vector Laboratories, Burlingame, CA, USA). Photographs were taken with a SPOT ${ }^{\circledR}$ II (Diagnostic Instruments, Sterling Heights, MI, USA) digital camera.

\section{TUNEL}

Slides were prepared and fixed as above. For end labeling DNA fragments, the Apoptosis Detection System, Fluorescein (Promega), was used according to the manufacturer's protocol. For double labeling with TUNEL and anti-PARP p85 fragment $\mathrm{pAb}$, the slides were rinsed in PBS after TUNEL and then treated as above for immunocytochemistry.

\section{RESULTS AND DISCUSSION}

\section{Anti-PARP p85 pAb Specifically Immunostains Apoptotic Jurkat Cells}

To generate an antibody that is specific for cleaved PARP and does not recognize intact PARP, a short sequence on the C-terminal side of the caspase-3 cleavage site was used as an immunogen (Figure 1). We have previously shown by western blot that the anti-PARP p85 fragment pAb is specific for the caspase-cleaved fragment of human and bovine PARP but does not recognize full-length human or bovine PARP (Figure 3, bottom) (21). The specificity of the antibody suggested that it would be a useful immunocytochemical marker for apoptosis. The specificity for human and bovine PARP, despite two amino acid changes in the immunogen sequence (Figure 1), suggested that the antibody would be a useful tool for monitoring apoptosis in several model organisms.

We used anti-Fas-induced apoptosis in human Jurkat cells as the model system to test the antibody as an in situ marker of apoptosis. Jurkat cells were treated with the anti-Fas mAb for $6 \mathrm{~h}$ or were left untreated as a control. Many of the anti-Fas $\mathrm{mAb}$-treated cells were strongly labeled with the anti-PARP p85 fragment pAb (Figure 2C), whereas the untreated cells had virtually no background staining (Figure 2A). DAPI staining revealed condensed chromatin and apoptotic bodies in the anti-Fas-treated cells, indicating the morphology of apoptosis (Figure 2, B and D). Interestingly, the anti-PARP p85 staining was segregated from the DAPI-labeled condensed chromatin within most apoptotic cells (Figure 2, C and D). Recently, the antibody also has been used to label cleaved PARP in rabbit (19), mouse (25), and human tissue (11).

\section{Apoptotic Events Monitored in Anti-Fas mAb-Treated Jurkat Cells Using Anti-PARP p85 pAb, DAPI, and TUNEL}

Co-localization of anti-PARP p85 immunostaining and TUNEL was used to confirm that the anti-PARP p85 pAb is specific for apoptotic cells (Figure 3). However, DNA fragmentation is a late-stage nuclear event. Caspase activation precedes DNA fragmentation, so we expected to detect cleaved PARP with the anti-PARP p85 pAb before we detected TUNEL-positive cells. To determine the relationship between TUNEL and anti-PARP p85 immunoreactivity, we performed a time course of anti-Fas mAb treatment of Jurkat cells and then monitored for apoptosis with both TUNEL and anti-PARP p85 pAb (Figure 3). Treatment times of $30 \mathrm{~min}$, $1.5 \mathrm{~h}, 3 \mathrm{~h}$, and $6 \mathrm{~h}$ were assessed. There was no TUNEL staining above background at $30 \mathrm{~min}$ (Figure 3B) and very few

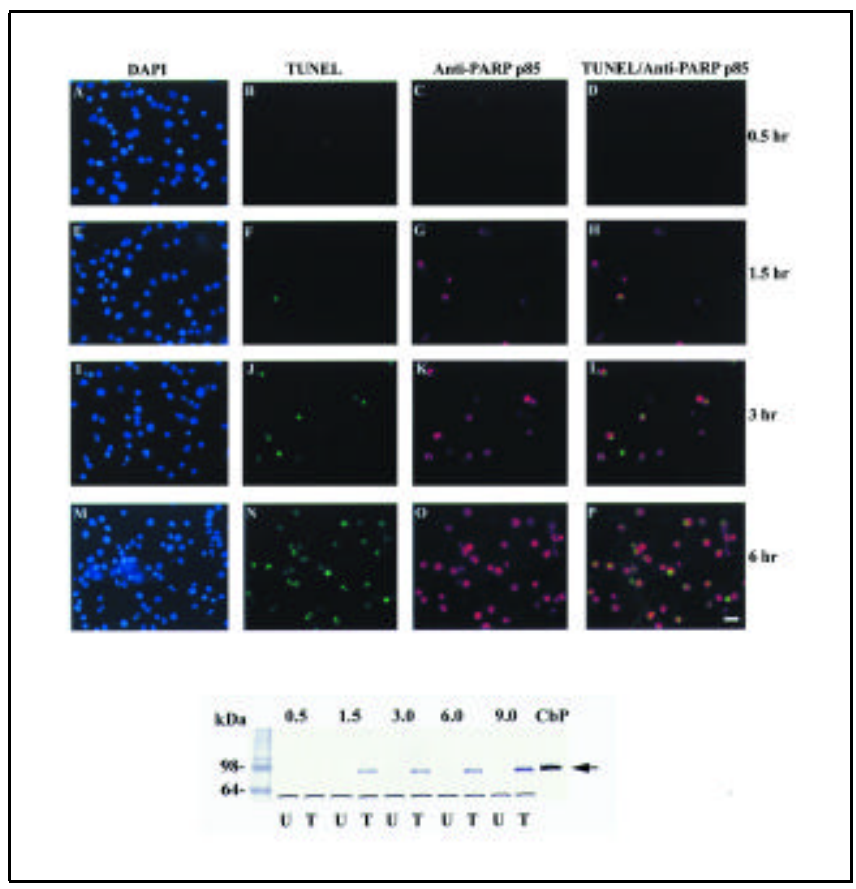

Figure 3. A time course of anti-Fas treatment of Jurkat cells. Top, double labeling with TUNEL and anti-PARP p85 fragment pAb. Jurkat cells were treated with anti-Fas for the times noted. Each row shows the same field of cells at the noted time point. Each column shows a different staining method as noted. For each time point, the DAPI staining shows the number of nuclei in each field. Scale bar $=20 \mu \mathrm{m}$. Bottom, western blot of cleaved PARP. Jurkat cells were either untreated (U) or treated with anti-Fas $(\mathrm{T})$ for the times noted. Lysates were made, and $10 \mu \mathrm{g}$ protein were loaded per lane. Caspase-3-cleaved purified bovine PARP (CbP) was used as a positive control. In extracts of untreated cells or after $0.5 \mathrm{~h}$ of treatment, there was no band migrating with the cleaved PARP. After $1.5 \mathrm{~h}$ of treatment, there was a band corresponding to the cleaved PARP. This band was also present in extracts from cells treated for 3,6 , or $9 \mathrm{~h}$. There is an unidentified, approximately $60-\mathrm{kDa}$ band observed in all extracts. 
cells at $1.5 \mathrm{~h}$ of anti-Fas mAb treatment (Figure 3E). At $3 \mathrm{~h}$ of anti-Fas mAb treatment, there were clearly TUNEL-positive cells above background (Figure 3J). The number of cells that were TUNEL positive increased at $6 \mathrm{~h}$ of treatment (Figure $3 \mathrm{~N}$ ) and appeared to reach a maximum at $9 \mathrm{~h}$ (not shown). The anti-PARP p85 labeling followed a similar pattern, but more cells were stained at the earlier time points. Cleaved PARP was not detected after $30 \mathrm{~min}$ of anti-Fas treatment, but there was significant staining over background at $1.5 \mathrm{~h}$ of treatment (Figure 3G). A majority of these cells were not TUNEL positive (Figure 3F). The number of stained cells reached a maximum at $6 \mathrm{~h}$ (Figure 30). Double labeling revealed that, by $6 \mathrm{~h}$ of anti-Fas mAb treatment, virtually all of the anti-PARP p85-labeled cells also were TUNEL positive (Figure 3P). These results confirmed that the anti-PARP p85 $\mathrm{pAb}$ could detect apoptotic cells before DNA fragmentation and TUNEL. In addition, it can be used in conjunction with TUNEL to confirm apoptosis at later stages of apoptosis.

Extracts were made for western analysis from the same populations of cells treated with the anti-Fas mAb for various times above. The western blot revealed that, after $30 \mathrm{~min}$ of anti-Fas treatment, there was no detectable PARP cleavage in $10 \mu \mathrm{g}$ extract. At $1.5 \mathrm{~h}$ of treatment, there was a strong band of anti-PARP labeling at $85 \mathrm{kDa}$ in the treated extracts but not in the untreated (Figure 3, bottom, arrow). This corresponds to the first time point when cleaved PARP was detected in the immunocytochemistry time course (Figure 3 ). The western blot results revealed strong bands in the treated cell extracts for the rest of the time course, while there were no bands at 85 $\mathrm{kDa}$ in the untreated extracts. The cleaved bovine PARP $(\mathrm{CbP})$ was used as a positive control (Figure 3, bottom, arrow). An unknown $60-\mathrm{kDa}$ band is present in all the extracts; however, its epitope may be present only under denaturing conditions because it did not interfere with immunocytochemical staining (Figures 2 and 3). We have previously shown that caspase activity, monitored with the Ac-DEVDpNA substrate, closely corresponded to the immunocytochemistry results. There was no detectable caspase activity after $30 \mathrm{~min}$ of anti-Fas treatment, but then it increased significantly until $6 \mathrm{~h}$ and leveled off (18).

\section{Caspase-Cleaved PARP p85 Fragment Does Not Co-Localize with DAPI or a Cytoplasmic Marker}

Currently, there is considerable interest in monitoring the localization of PARP and its cleaved fragments because of recent suggestions that PARP may have functions in addition to its DNA repair role $(1,3,15,16)$. Before the development of this specific anti-PARP p85 antibody, it had been difficult to determine what happens to the PARP fragments once they are cleaved. The DEVD caspase recognition site for cleaving PARP occurs in the nuclear localization signal of PARP (6, 24). It has been suggested that the 24-kDa PARP fragment containing the DNA binding domain remains bound irreversibly to DNA fragments (28), but it was not clear what happened to the C-terminal p85 fragment.

One study reported that PARP was initially distributed in both the nucleus and the cytoplasm in SH-SY5Y neuroblastoma cells, but after staurosporine treatment, the staining became associated with condensed chromatin (20). This is in contrast to our studies with Jurkat cells. The cells double labeled with either DAPI/anti-PARP p85 (Figure 2) or TUNEL/ anti-PARP p85 (Figure 3) revealed that the p85 PARP frag- ment generally was not co-localized with the condensed chromatin. However, it was difficult to tell whether the staining was perinucleolar or cytoplasmic because the cytoplasm in Jurkat cells is minimal. We further characterized the localization of the cleaved PARP p85 fragment using the SH-SY5Y human neuroblastoma cells, the same cells used in the earlier study (20). SH-SY5Y human neuroblastoma cells were treated with staurosporine to induce apoptosis. Untreated controls and staurosporine-treated cells were then double labeled with anti-PARP p85 pAb and an anti- $\beta$ III tubulin mAb (Figure 4). Anti- $\beta$ III tubulin specifically labels neuronal cytoplasm. Staurosporine-treated SH-SY5Y cells were strongly labeled with the anti-PARP p85 pAb (Figure 4A). We found that at the earliest apoptotic stages, when there were no associated morphological markers, the anti-PARP p85 staining was distributed evenly in the nucleus. However, quite rapidly, as soon as the chromatin began condensing at the nuclear periphery, the staining was isolated from the DAPI-positive condensed chromatin (Figure 4, A and B). However, double labeling with the anti- $\beta$ III tubulin $\mathrm{mAb}$ showed that this anti-PARP p85 staining was not cytoplasmic (Figure 4D). At very late stages of apoptosis, the $\beta$ III tubulin marker was not visible, so the localization could not be determined. These results indicated that the $\mathrm{p} 85$ fragment became rapidly dissociated from the condensed chromatin but was retained in the nucleus at least as long as the cytoplasm was morphologically distinct. Our results are consistent with recent reports in HeLa cells (1) and HL-60 cells (14).

Using an antibody specific to the caspase-cleaved PARP p85 fragment, we have been able to monitor its localization during apoptosis. Our results in both anti-Fas-treated Jurkat cells and staurosporine-treated human neuroblastoma cells support the recent hypothesis by Alvarez-Gonzalez et al. (1) that this fragment is rapidly translocated from nucleoli during apoptosis and may function specifically in the nucleoplasm to
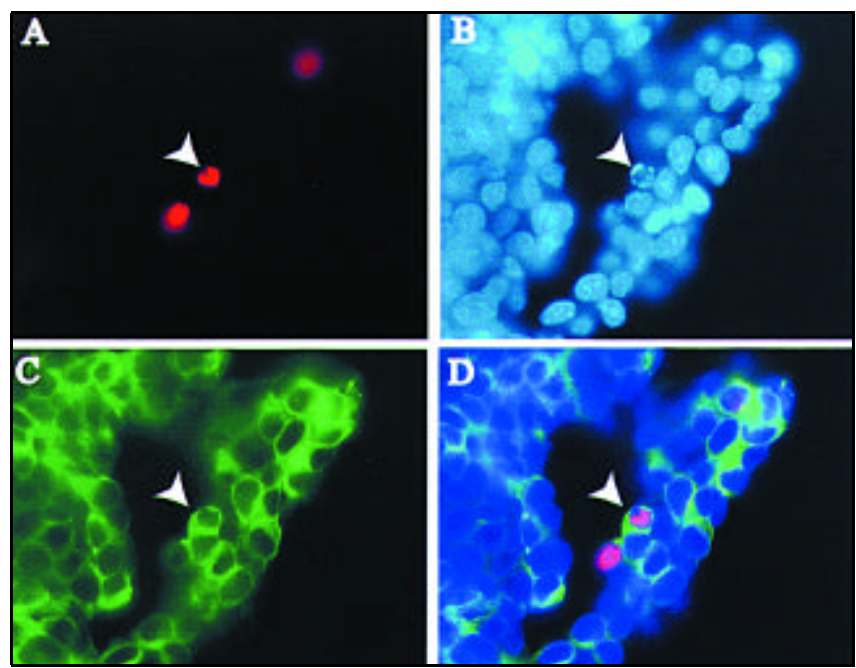

Figure 4. Localization of the PARP p85 fragment in staurosporine-treated SH-SY5Y cells. An example of SH-SY5Y cells treated with $0.5 \mu \mathrm{M}$ staurosporine cells for $1 \mathrm{~h}$ is shown with anti-PARP p85 pAb staining (A), DAPI staining (B), and anti- $\beta$ III tubulin staining $(C)$. The arrowhead points to an anti-PARP p85-positive cell (A) with condensed chromatin (B). The antiPARP p85 staining is distinct from the condensed chromatin (A and $\mathrm{B}$ ) but is not in the cytoplasm, as shown with the anti- $\beta$ III tubulin staining (C). The triple labeling (D) illustrates the lack of correspondence among the DAPIstained condensed chromatin, the anti-PARP p85 staining, and the cytoplasmic anti- $\beta$ III tubulin staining. 
modulate protein-protein interactions. An antibody specific for the caspase-cleaved fragment of PARP can be used to monitor apoptosis and address questions regarding the role of PARP in apoptosis.

\section{REFERENCES}

1.Alvarez-Gonzalez, R., H., Spring, M. Muller, and A. Burkle. 1999. Selective loss of poly(ADP-ribose) and the 85-kDa fragment of poly(ADPribose) polymerase in nucleoli during alkylation-induced apoptosis of HeLa cells. J. Biol. Chem. 274:32122-32126.

2.Ame, J.C., V. Rolli, V. Schreiber, C. Niedergang, F. Apiou, P. Decker, S. Muller, T. Hoger, J. Menissier-de Murcia, and G. de Murcia. 1999. PARP-2, a novel mammalian DNA damage-dependent poly (ADP-ribose) polymerase. J. Biol. Chem. 274:17860-17868.

3.Cookson, M.R., P.G. Ince, P.A. Usher, and P.J. Shaw. 1999. Poly(ADP)ribose polymerase is found in both the nucleus and cytoplasm of human CNS neurons. Brain Res. 834:182-185.

4.D'Amours, D., M. Germain, K. Orth, V.M. Dixit, and G.G. Poirier. 1998. Proteolysis of poly (ADP-ribose) polymerase by caspase 3: kinetics of cleavage of mono (ADP-ribosyl)ated and DNA-bound substrates. Radiation Res. 150:3-10.

5.D'Amours, D., S. Desnoyers, I. D'Silva, and G.G. Poirier. 1999. Poly (ADP-ribosyl) ation reactions in the regulation of nuclear functions. Biochem. J. 342:249-268.

6.Duriez, P.J. and G.M. Shah. 1997. Cleavage of poly(ADP-ribose) polymerase: a sensitive parameter to study cell death. Biochem. Cell Biol. 75:337-349.

7.Germain, M., E.B. Affar, D. D'Amours, V.M. Dixit, G.S. Salvesen, and G.G. Poirier. 1999. Cleavage of automodified poly(ADP-ribose) polymerase during apoptosis: evidence for involvement of caspase-7. J. Biol. Chem. 274:28379-28384.

8.Guo, T.L., M.A. Miller, I.M. Shapiro, and B.J. Shenker. 1998. Mercuric chloride induces apoptosis in human T lymphocytes: evidence of mitochondrial dysfunction. Toxicol. Appl. Pharmacol. 153:250-257.

9.Joashi, U.C., K. Greenwood, D.L. Taylor, M. Kozma, N.D. Mazarakis, A.D. Edwards, and H. Mehmet. 1999. Poly(ADP ribose) polymerase cleavage precedes neuronal death in the hippocampus and cerebellum following injury to the developing rat forebrain. Eur. J. Neurosci. 11:91-100.

10.Kangas, A., D.W. Nicholson, and E. Hottla. 1998. Involvement of CPP32/Caspase-3 in c-Myc-induced apoptosis. Oncogene 16:387-398.

11.Knaapen, M., M. De Bie, J. Muhring, and M. Kockx. 1999. Cleaved PARP as a marker for apoptosis in tissue sections. Promega Notes 72:7-9.

12.Lazebnik, Y.A., S.H. Kaufmann, S. Desnoyers, G.G. Poirier, and W.C. Earnshaw. 1994. Cleavage of poly (ADP-ribose) polymerase by a proteinase with properties like ICE. Nature 371:346-347.

13.Leers, M.P.G., W. Kolgen, V. Bjorklund, T. Bergman, G. Tribbick, B. Persson, P. Bjorklund, F.C.S. Ramaekers et al. 1999. Immunocytochemical detection and mapping of a cytokeratin 18 neo-epitope exposed during early apoptosis. J. Pathol. 187:567-572.

14.Li, X. and Z. Darzynkiewicz. 2000. Cleavage of poly(ADP-ribose) polymerase measured in situ in individual cells: relationship to DNA fragmentation and cell cycle position during apoptosis. Exp. Cell Res. 255:125-132.

15.Love, S., T. Barber, and G.K. Wilcock. 1999. Increased poly(ADP-ribosyl)ation of nuclear proteins in Alzheimer's disease. Brain 122:247-253.

16.Malanga, M., J.M. Pleschke, H.E. Kleczkowska, and F.R. Althaus. 1998. Poly (ADP-ribose) binds to specific domains of p53 and alters its DNA binding functions. J. Biol. Chem. 273:11839-11843.

17.Nicholson, D.W., A. Ali, N.A. Thornberry, J.P. Vaillancourt, C.K. Ding, M. Gallant, Y. Garear, P.R. Griffin et al. 1995. Inactivation of poly (ADP-ribose) polymerase at the onset of apoptosis is mediated by the ICE/CED-3-like cysteine protease, CPP32. Nature 376:37-43.

18. Okragly, A. and M. O'Brien. 1999. Death Check ${ }^{\mathrm{TM}}$ assay systems for monitoring apoptosis. Promega Notes 72:3-6.

19.Perng, G-C., C. Jones, J. Ciacci-Zanella, M. Stone, G. Henderson, A. Yukht, S.M. Slanina, F.M. Hofman et al. 2000. Virus-induced neuronal apoptosis blocked by the herpes simplex virus latency-associated transcript. Science 287:1500-1503.

20.Postmantur, R., K. McGinnis, R. Nadimpalli, R.B. Gilbertson, and K.K.W. Wang. 1997. Characterization of CPP32-like protease activity following apoptotic challenge in SH-SY5Y neuroblastoma cells. J. Neurochem. 68:2328-2337.

21.Promega Corporation. 1999. Anti-PARP p85 Fragment pAb Technical Bulletin no. 273
22.Rasper, D.M., J.P. Vaillancourt, S. Hadano, V.M. Houtzager, I. Seiden, S.L.C. Keen, P. Tawa, S. Xanthoudakis et al. 1998. Cell death attenuation by "Usurpin", a mammalian DED-caspase homologue that precludes caspase- 8 recruitment and activation by the CD-95 (Fas, APO-1) receptor complex. Cell Death Diff. 5:271-288.

23.Saldeen, J. and N. Welsh. 1998. Nicotinamide-induced apoptosis in insulin producing cells is associated with cleavage of poly (ADP-ribose) polymerase. Mol. Cell Endocrinol. 139:99-107.

24.Sallmann, F.R., S. Bourassa, J. Saint Cyr, and G.G. Poirier. 1997. Characterization of antibodies specific for the caspase cleavage site on poly(ADP-ribose) polymerase: specific detection of apoptotic fragments and mapping of the necrotic fragments of poly(ADP-ribose) polymerase. Biochem. Cell Biol. 75:451-456.

25.Schmidt-Supprian, M., W. Bloch, G. Courtois, K. Addicks, A. Israel, K. Rajewsky, and M. Pasparakis. 2000. NEMO/IKKy-deficient mice model incontinentia pigmenti. Mol. Cell 5:981-992.

26.Shah, G.M., R.G. Shah, and G.G. Poirier. 1996. Different cleavage pattern for poly (ADP-ribose) polymerase during necrosis and apoptosis in HL-60 cells. Biochem. Biophys. Res. Commun. 229:838-844.

27.Simbulan-Rosenthal, C.M., D.S. Rosenthal, S. Iyer, A.H.Boulares, and M.E. Smulson. 1998. Transient poly(ADP-ribosyl)ation of nuclear proteins and role of poly (ADP-ribose) polymerase in the early stages of apoptosis. J. Biol. Chem. 273:13703-13712.

28.Smulson, M.E., D. Pang, M. Jung, A. Dimtchev, S. Chasovskikh, A. Spoonde, C. Simbulan-Rosenthal, D. Rosenthal, A. Yakovlev, and A. Dritschilo. 1998. Irreversible binding of poly(ADP) ribose polymerase cleavage product to DNA ends revealed by atomic force microscopy: possible role in apoptosis. Cancer Res. 58:3495-3498.

29.Srinivasan, A., K.A. Roth, R.O. Sayers, K.S. Shindler, A.M. Wong, L.C. Fritz, and K.J. Tomaselli. 1998. In situ immunodetection of activated caspase-3 in apoptotic neurons in the developing nervous system. Cell Death Diff. 5:1004-1016.

30.Tewari, M., L.T. Quan, K. O'Rourke, S. Desnoyers, Z. Zeng, D.R. Beidler, G.G. Poirier, G.S. Salvesen, and V.M. Dixit. 1995. Yama/Cpp32b, a mammalian homolog of CED-3, is a crmA-inhibitable protease that cleaves the death substrate poly (ADP-ribose) polymerase. Cell 81:801809.

31.Thornberry, N. and Y. Lazebnik. 1998. Caspases: enemies within. Science 281:1312-1316.

32.Trucco, C., F.J. Oliver, G. de Murcia, and J. Menissier-de Murcia. 1998. DNA repair defect in poly (ADP-ribose) polymerase-deficient cell lines. Nucleic Acids Res. 26:2644-2649.

33.Weis, M., J. Schlegel, G.E. Kass, T.H. Holmstrom, I. Peters, J. Eriksson, S. Orrenius, and S.C. Chow. 1995. Cellular events in Fas/APO-1mediated apoptosis in JURKAT T lymphocytes. Exp. Cell Res. 219:699708.

34. Yang, F., S. Sun, W. Beech, B. Teter, S. Wu, J. Sigel, H.V. Vinters, S.A. Frautschy, and G.M. Cole. 1998. Antibody to caspase-cleaved actin detects apoptosis in differentiated neuroblastoma and plaque-associated neurons and microglia in Alzheimer's disease. Amer. J. Pathol. 152:379-389.

35.Yuan, J., S. Shaham, S. Ledoux, H.M. Ellis, and H.R. Horvitz. 1993. The $C$. elegans cell death gene ced-3 encodes a protein similar to mam malian interleukin-1 beta-converting enzyme. Cell 75:641-652.

Address correspondence to Dr. Martha O'Brien, Promega Corporation, 2800 Woods Hollow Rd., Madison, WI 53711, USA,e-mail:mobrien@promega.com 